\title{
Job and housework during radiotherapy: Comparisons between leaving out activities and disease treatment
}

\author{
Cristiane Helena Gallasch ${ }^{1 *}$, Neusa Maria Costa Alexandre ${ }^{1}$, Sergio Carlos Barros Esteves $^{2}$ \\ ${ }^{1}$ Faculty of Nursing, State University of Campinas, São Paulo, Brazil; * Corresponding Author: cristiane_gallasch@yahoo.com.br \\ ${ }^{2}$ Department of Tocogynecology, CAISM Hospital of Women Dr. José Aristodemo Pinotti, State University of Campinas, São Paulo, Brazil
}

Received 16 April 2013; revised 20 May 2013; accepted 11 June 2013

Copyright (C) 2013 Cristiane Helena Gallasch et al. This is an open access article distributed under the Creative Commons Attribution License, which permits unrestricted use, distribution, and reproduction in any medium, provided the original work is properly cited.

\begin{abstract}
Background: Researches about work limitations related to cancer treatment and survival are recent. This study describes the characteristics of patients who keep their work and house work activities during radiotherapy, and comparison between some disease data and leaving out those activities. Methods: Data were collected from medical records of patients admitted in a Brazilian Radiotherapy Private Health Service. Descriptive statistical analysis was performed, as hypotheses texts, Chi-square and Fisher's exact test. Results: Data of 111 individuals were presented; being $65.77 \%$ of workers of paid activities and $34.34 \%$ of careers of home. Between employees, $50.7 \%$ kept their job activities, and 92.1\% between house workers. The association between absence from work activities and tumor type (primary or metastasis) and between absence and KPS $(p<0.05)$ were observed. Discussion: It is observed that breast, brain and lung tumors significantly affect employees' performance, causing the withdrawal of workers from their activities. Data from the literature review clearly demonstrated the importance of work activities in social support of the worker, but his overall performance may be impaired. Implications for cancer survivors: The study indicates the need for assessment of the individual, work or activity environment and required as well as the continuity research aiming at the development and validation of evaluation tools such as questionnaires or scales.
\end{abstract}

Keywords: Radiation Therapy; Cancer
Survivorship; Return to Work; Occupational Health Nursing

\section{BACKGROUND}

Currently, due to the possibility of early detection and effective treatments, people are living with chronic diseases, such as cancer, musculoskeletal disorders, arthritis, heart disease or neurological impairments, representing a serious public health problem and causing functional limitations and bio-psycho-social changes [1-5].

In 2008, there were 12 million new cancer cases worldwide, with seven million deaths. The International Association for Research on Cancer (IARC) and World Health Organization (WHO) estimate that half of new cases and two thirds of deaths occur in low income and developing countries. It is estimated that the number of new cases in 2020 will be around 15 million, about $60 \%$ of new cases occurring in developing countries [6].

In Brazil, cancer is an important cause of morbidity and mortality, accounting in 2007, $17 \%$ of known causes of death reported to the Brazilian Mortality Information System, representing 159.092 deaths. Until 2012, December, 518.510 new cases were expected. The highest incidences should be observed for prostate and lung cancer for men and breast and cervix for women, except for the cancer non-melanoma skin type. The same is expected in the Latin America [6].

Cancer survival must be considered as important as medical treatment, since, due to increased prevalence, it is necessary to prevent the challenges that come forward to "live with a cancer diagnosis" [7]. These patients complete a primary cycle of treatment and there is the possibility of maintaining a long survival, keeping their daily activities and work.

Advances in cancer treatment give changes for patients, as well as for those who have other chronic disor- 
ders or disabilities. Discrimination against labor activities is not permitted and there were great advances to promote legal rights and to ensure quality of work life for cancer survivors. The sustenance of work activities offers advantages, including remuneration, medical care and a potential social support [8].

Studies have identified cognition problems sometimes related to disease's symptoms, like fatigue and depression [9]. The occurrence of long-term sick-leave is related in patients who had treatments like surgery, chemotherapy, radiotherapy or other combinations, because of changes in overall working ability, mental work ability and lack of supervisor's support at work, which could be different with interventions of health care personnel [10].

In a research including a heterogeneous group in terms of types of cancer, Yabroff et al. [11] indicate that, even eleven years after cancer diagnosis, still there may be limitations at work. Feuerstein et al. [12] indicate significant work limitations in individuals with many types of cerebral cancer, due to fatigue, depression, anxiety and cognitive factors, after a study using the Work Limitations Questionnaire (WLQ).

Similar limitations were observed by Hansen et al. [13] when studying patients with thoracic cancer diagnosis, even four years after the beginning of treatment.

Radiotherapy is an effective treatment option for many cancer diagnoses, which has been used alone or combined with surgery or chemotherapy, with high survival rates [14]. In Europe, it is estimated approximately 70\% of patients with cancer used radiotherapy. Primary tumors account for $60 \%$ of the proposed treatments [15]. There are no published data on these aspects for the Brazilian population, estimating in clinical practice the use for $60 \%$ of patients at some stage of treatment.

There are different side effects related to damage to organs and structures involved in the field of application during treatment, including acute and late effects [14].

Health professionals should be alert to changes resulting from radiotherapy, by working on protective measures to decrease side effects, providing for patients information about treatment, considering possible discomfort and directing action to relieve them, also promoting support for reducing anxiety and depression [16].

Due to recent researches that evidence aspects related to cancer survival and the need of planning the return to work during and after treatment, it's necessary to enhance recognition of this population, to identify their needs, side effects and difficulties to maintain or return for their work activities, and to develop or improve instruments for their assessment.

Research involving work limitations related to cancer treatment and cancer survival is recent. Professionals in occupational health need information and skills to facili- tate changes in the workplace and develop actions to improve these frameworks and facilitating return to work.

The identification of work activities and the major types of cancers that allow or interfere preventing the continuation of that is the initial step for future specific evaluations, as the validation of assessment tools and action planning to enable the return to work early, even when this is not occurring during the removal of these patients from the workplace.

This aim of this study was to identify patients who keep their work activities even during radiotherapy, and identify and describe types of activities developed and social-demographic characteristics of this population. Later, statistical comparisons were accessed: between absence of work activities and the occurrence of primary or metastasis disease, body region treated and type of work. During the study, housekeeping tasks seemed to be an important activity and were also studied.

\section{METHODS}

\subsection{Study Design}

It's a retrospective study, with documentary research, using medical records, conducted in a private radiotherapy service, in Campinas, São Paulo, Brazil. Data were searched directly the charts.

Inclusion criteria include patients older than 18 years, with cancer diagnosis confirmed by laboratorial evaluation, with indication radiotherapy in the modality of teletherapy, acting in professional activities remunerated formal or informal, declared during medical or nursing appointments.

Exclusion criteria were retirement, indication radiotherapy in the modality of brachytherapy, or teletherapy for treatment of benign diseases, lack of data in medical records about type work activity, and absence from work during the proposed treatment.

\subsection{Sample Size}

Between September 2009 and February 2010, 229 patients were admitted in the radiotherapy service, being 111 of these were included in the study, after evaluation of their medical records. The specific sample size was obtained from the data selection, considering the criteria for inclusion and exclusion in the research.

\subsection{Assessment Toll}

A form based on previous research [17] was used to collect socio-demographic and clinical information, including age, gender, diagnosis, treatment area, work activities, classification of the type of work, Performance Status Coefficient-Karnofsky (KPS). 
Treatment area refers to a topographical division of body segments based on anatomical references: head and neck, thorax (including breast and lung), abdomen, pelvis, limbs (upper and lower), spine and central nervous system.

The classification of work was done as proposed by Hébert in 1996 [16] and that has been used in previous studies about workers' health $[17,19]$.

Karnofsky scale, or Performance Status Coefficient, is use as a systematic evaluation and registration of the patient's status in oncology, demonstrated in right values, as if $60,70,80,90$ or 100 [20]. KPS values recorded in medical or nursing care was considered.

\subsection{Statistical Analysis}

Data were analyzed descriptively by absolute and relative frequencies for categorical variables. To check differences between groups for the same parameters (age, KPS) t-student test was used [21].

To assess the association between absence of work activities and performance evaluation by the Karnofsky Coefficient, and the body region treated, and the tumor type-primary or metastasis, and type of work were used the chi-square test of association for nominal variables and Fisher's exact test, used when it is not possible to evaluate with the previous test [21].

All tests were evaluated with 95\% significance level ( $\alpha=5 \%)$.

Microsoft Office Excel 2007 and SPSS 17.0.0 Statistics 2008 were used for data organization and classification.

\subsection{Study Limitations}

It wasn't possible to create a control group to compare populations is a limitation of this study.

Because of many types of diagnoses, what could break the sample, subgroups was not created for others statistical analyses.

Survey obtained the approval of the Institution's Committee of Ethics in Research.

The study is linked to the Group for Study and Research in Occupational Health and Ergonomics-Directory of Research Groups in Brazil (CNPq).

There was no conflict of interest.

\section{RESULTS}

According to the data, 111 patients admitted between September 2009 and February 2010 maintained their activities, being 73 (65.77\%) classified as employees (formal or informal) and 38 (34.23\%) called "House workers" that are responsible for the tasks of caring for the home.

Due to the large number of patients who maintain the care of their homes, and the physical demands and psy- chosocial tasks involved in this activity, they were included in the survey and are described below as house workers.

Data presented in Table 1 refer to the age and performance evaluation using the Karnofsky Coefficient for the subjects. There is a statistically significant difference between groups for these variables.

Regarding the treatment area, there is a predominance of diagnoses related to the thoracic regions, with $45.2 \%$ among employees and $47.4 \%$ among house workers; and pelvis, with $24.7 \%$ among employees and $31.6 \%$ in those who perform activities of care to their own residence.

About work activities, most employees performing nonmanual functions (39.7\%), followed by manual activity (31.5\%) and mixed (28.8\%). The group of house workers executes $100 \%$ manual activity.

It was observed that $50.7 \%$ of employees and $92.1 \%$ of house workers kept their activities even after diagnosis and beginning of treatment.

Among the cases involved in the treatment and absence, it was observed that 36 patients (35.14\%) were away from their usual activities. Of all patients in treatment, absence occurred in $9.01 \%$ of these due to breast cancer, 5.41\% for cases involving brain and 3.60\% in the treatment of the lung.

In the assessment only group of patients absented of their activities, there are the cancer of breast, brain and lung appears in the majorly of the cases (25.64\%, $15.38 \%$ and $10.26 \%)$.

It wasn't observed absence for patients in radiotherapy for stomach, hypopharynx, larynx, orbit, pancreas, parotid and skin cancer.

About evaluation of the association between absence from activities and treatment area, absence and performance by the Karnofsky Coefficient, absence and tumor type and absence and type of work performed, data are presented in Tables 2 and 3.

It's was observed association between absence from work activities and tumor type (primary or metastasis) and between absence and KPS ( $\mathrm{p}<0.05)$.

There wasn't association between leaving out home activities and KPS, treatment area or tumor type because majorly of people kept their activities.

Table 1. Age (years) and Karnofsky Coefficient (\%) of employees and house workers of home in radiotherapy, 2010.

\begin{tabular}{ccccc}
\hline & \multicolumn{2}{c}{ Employees $(\mathrm{n}=73)$} & \multicolumn{2}{c}{ House workers $(\mathrm{n}=38)$} \\
\cline { 2 - 5 } & Range & Mean & Range & Mean \\
\hline $\begin{array}{c}\text { Age } \\
\text { (years) }\end{array}$ & $26-80$ & $48.51( \pm 11.60)$ & $27-89$ & $62.70( \pm 15.11)$ \\
KPS (\%) & $50-100$ & $86.43( \pm 12.46)$ & $70-100$ & $87.08( \pm 9.54)$ \\
\hline
\end{tabular}


Table 2. Association tests related to absence from work activities, 2010.

\begin{tabular}{ccc}
\hline Association test & p-value & Evaluation \\
\hline Absence $\times$ treatment area & $0.215^{*}$ & No association \\
Absence $\times$ performance (KPS) & $0.0014^{*}$ & Association \\
Absence $\times$ tumor type & $0.024^{* *}$ & Association \\
Absence $\times$ type of work performed & $0.692^{*}$ & No association \\
\hline${ }^{*}$ Qui-Square test; ${ }^{* *}$ Fisher exact test. & &
\end{tabular}

Table 3. Association tests related to absence from home activities, 2010.

\begin{tabular}{ccc}
\hline Association test & p-value & Evaluation \\
\hline Absence $\times$ treatment area & $0.145^{*}$ & No association \\
Absence $\times$ performance (KPS) & $0.552^{*}$ & No association \\
Absence $\times$ tumor type & $0.224^{* *}$ & No association \\
\hline
\end{tabular}

*Qui-Square test; ${ }^{* *}$ Fisher exact test.

\section{DISCUSSION}

In this study it was observed that $48.47 \%$ of patients keep their activities during radiotherapy. Of these, $65.77 \%$ are employees of paid work and $34.23 \%$ are house workers.

In Brazil, in the speech of several patients and health professionals, its common the intention directed to withdraw from professional activities, by seeking financial aid, such as disability compensation from the Brazilian Institute of Social Security (INSS), during following the treatment of several chronic diseases.

Regarding to the age of patients in radiotherapy, there are means of 48,51 years among workers and 62,70 years among house workers.

In that country, it's common to find people still working with age above 70 or even 80 years old, because of low salaries in retirement.

The group of employees reflects the trend of change in the age group of individuals with cancer diagnosis. A process that was previously understood as a disease of the senescence stage now is an early diagnosis.

This new standard is due to easy access to medical appointments and the availability of more accurate and detailed examinations. However, changes in life patterns and behavior, with exposure to risk factors in family or life style, society, or at work are crucial in changing the patterns of outbreaks of these diseases.

There was a similar number of workers performing non-manual, manual and mixed activities, with no statistical difference. The group of house workers executes presents majority of women, with manual activity, because of the need to take care home and family.
Treatment focused on the primary disease, $84.9 \%$ in the group of employees and $92.1 \%$ of house workers, follows the trend observed in other countries [15].

The prevailing treatment of thoracic and pelvic regions in the topographic classification used follows the pattern of Brazilian reality, where the tumors more insidious are breast and uterus in females and lung and prostate for males [6].

Recent improvements in the treatment of cancers in general have improved both the conditions of survival and maintenance skills to work well during the course of treatment [22]. But not always the diagnosis and treatment for cancer leads to disabilities. When that occurs, it is possible to fit the environment for re-integration or adaptation of the environment to the needs of the worker.

Shares of health promotion and rehabilitation should be studied and planned for different groups of cancer survivors, since the attention focused on the physical functions and for all possible functional limitations [23].

Other important aspects are related to social functions and mental health at work. In routine care appointments, patients verbally expressed "sadness" for not exercising their professional activities, thinking he/her had the same physical and mental conditions to do this.

The social circle formed, as well as the representation of position and status when maintained activities during treatment may contribute to personal satisfaction and better coping of the treatment period, when it's possible.

Family members and caregivers are also included within this context, represents an important tool to help and support people with cancer, encouraging development and maintenance of treatment and encouraging the implementation of other recreational activities and social events.

Bocchi and Angelo [24] highlight the importance of support from the health team and also to family caregivers, not just for the patient, due to this important role in the routine of the patient.

The survival after cancer diagnosis does not mean being free of side effects of the same or their treatments or their physical and psychosocial consequences [25].

Stress and depression should not be disregarded, being non-physical limiting factors, but that can lead to a real need for removal and monitoring by specialists.

While those who have paid working seek reports and medical records to attempt to leave the job during treatment, it appears that the people responsible for the care of the house does not cease to perform its activities. Among all house workers admitted in the period, 92.1\% maintained their activities, whether characterized as type of job $100 \%$ manual.

In a study of Johnsson et al. [26] with women in treatment for breast cancer, workers in a market, it was found that the maintenance work during treatment was per- 
ceived by workers as a way to maintain a "normal life", highlighting the social support obtained in the workplace for employers and colleagues, which minimized the feeling of social exclusion after the diagnosis.

In practice it is shown the representation in family and society of the responsibility in carrying out these tasks, even during treatment of chronic diseases, especially among women.

This same group showed higher values in the evaluation of Karnofsky Performance Coefficient $(\mu=87.08 \pm$ 9.54), which reflects a greater willingness to care for the home, and did not represent a statistical association between the values of Karnofsky and absence from activities.

Proper evaluation of the health worker's during cancer treatment may be an appropriate tool for evaluation on the necessity or otherwise of the removal work activities and the use of the Karnofsky Coefficient can be one of the tools for this assessment.

Patients who keep their work activities during treatment for cancer are more likely to report the occurrence of fatigue and stress when compared to those not keeping their activities or do not return to work [22].

Considering these aspects, it is necessary to use tools and assessment methodologies to assess the overall health status of individuals and that assist in the redesign of activities and work environments.

People undergoing cancer treatment are more likely to have lower rates of recovery and ability when compared those healthy or suffering from other chronic diseases [27].

Some cancers have been reported as most commonly related to difficulties in performance of work activities, such as breast cancer and hematology. Examples of those that do not cause significant changes in the field of occupational cancer are the prostate and testis [27]. In this study, these latter two treatments were also among the least caused absence from work.

Malignancies related to central nervous system causing varying degrees of disabilities related to cognitive impairment or locomotors system. Frames cause lung impairment due to imbalance of homeostasis, and decline in general practitioner.

No association was found between absenteeism from work and treatment area and spacing and type of work performed for the group of employees. For the same group, there was association between absenteeism and Karnofsky Coefficient and absence and the tumor type (primary or metastasis).

Limitations for work in workers during cancer treatment are common and related to factors related to illness, treatment and work environment. These limitations can directly influence the return to work and its continuation after the end of treatment [28].
Kennedy et al. [29] indicate the need for reintegration of workers and a healthy and satisfying work routine, with the need for counseling and appropriate accommodations. These adjustments can be performed and supervised by health professionals.

Besides the adjustments to be promoted by employers, employees also need to be targeted. Clear communication can enable a positive experience of returning to work [30].

Importantly, the type of treatment, especially chemotherapy, has a significant impact on the ability to work and may take long time to show improvement. The improvement of the patients can take 18 or 24 months after diagnosis and initiation of treatment [27].

There aren't studies focused specifically on the relationship between radiation therapy and absence or return to work. Overall, articles are published relating the general disease framework or chemotherapy, which is considered more aggressive to the occupational activities.

\section{CONCLUSIONS AND IMPLICATIONS FOR CANCER SURVIVORS}

Researches involving return to work or maintenance of these activities in the workplace or home activities during cancer treatment are recent and not specifically related to radiotherapy.

Data from the reviewed literature demonstrated the importance of work activities in support of the social worker, but the overall performance might be impaired.

It is observed that the tumors of the breast, brain and lung significantly affect the performance of the employee, causing the withdrawal of workers from their activities.

For the patient responsible for the care of home, continuity of the activities has important social significance, especially the representation of family care.

Data indicate the need for individual assessment of workers, the working environment or activity required ongoing research aiming at the development and validation of evaluation tools such as questionnaires and scales.

Proper assessment using validated instruments and training of health professionals can provide data for adaptation of the work environment and clarification of employers and colleagues to encourage the return to work and continuation of these activities.

\section{REFERENCES}

[1] Yelin, E. and Calahan, L.F. (1995) The economic cost and social and psychological impact of musculoskeletal conditions. Arthritis \& Rheumatism, 38, 1351-1362. doi:10.1002/art.1780381002

[2] Lidgren B. (1998) The economic impact of musculoskeletal disorders. Acta Orthopaedica Scandinavica, 69, 58-60. 
[3] Courtney, T.K. and Webster, B.S. (1999) Disabling occupational morbidity in the United States. Journal of Occupational and Environmental Medicine, 41, 60-69. doi:10.1097/00043764-199901000-00010

[4] Amick, B.C., Lerner, D., Rogers, W.H., Rooney, T. and Katz, J. (2000) A review of health-related work outcome measures and their uses, and recommended measures. Spine, 25, 3152-3160.

doi:10.1097/00007632-200012150-00010

[5] Feuerstein, M. (2005) Introduction: The world challenge of work disability. Journal of Occupational Rehabilitation, 15, 451-452. doi:10.1007/s10926-005-8026-Z

[6] Instituto Nacional do Câncer (2009) Estimativa 2010: Incidência de câncer no Brasil. Ministério da Saúde, Rio de Janeiro.

[7] Feuerstein, M. (2007) Defining cancer survivorship. Journal of Cancer Survivorship, 1, 5-7.

[8] Hoffmen, B. (2005) Cancer survivors at work: A generation of progress. Cancer Journal for Clinicians, 55, 271280. doi:10.3322/canjclin.55.5.271

[9] Todd, B.L., Feuerstein, E.L. and Feuerstein M. (2011) When breast cancer survivors report cognitive problems at work. The International Journal of Psychiatry in Medicine, 42, 279-294. doi:10.2190/PM.42.3.d

[10] Gudbergsson, S.B., Torp, S., Floten, T., Fossa, S.D., Nielsen, R. and Dahl, A.A. (2011) A comparative study of cancer patients tiwh short and long sick leave after primary treatment. Acta Oncologica, 50, 381-9. doi:10.3109/0284186X.2010.500298

[11] Yabroff, R., Lawrence, W.F., Clauser, S., Davis, W.W. and Brown, M.L. (2004) Burden of illness in cancer survivors: Findings from a population-based national sample. Journal of the National Cancer Institute, 96, 1322-1330. doi:10.1093/jnci/djh255

[12] Feuerstein, M., Hansen, J.A., Calvio, L.C., Johnson, L. and Ronquillo, J.G. (2007) Work productivity in brain tumor survivors. Journal of Occupational and Environmental Medicine, 49, 803-811. doi:10.1097/JOM.0b013e318095a458

[13] Hansen, J.A., Feuerstein, M., Calvio, L.C. and Olsen, C.H. (2008) Breast cancer survivors at work. Journal of Occupational and Environmental Medicine, 50, 777-784. doi:10.1097/JOM.0b013e318165159e

[14] Perez, C.A. (1999) Perspectivas futuras em radioterapia. In: Salvajoli, J.V., Souhami, L. and Faria, S.L. Eds., $R a-$ dioterapia em Oncologia, Medsi, São Paulo, 1933, 1933.

[15] Ringborg, U., Bergqvist, D., Brorsson, B., Cavallin-Stahl, E., Ceberg, J., Einhorn, N., et al. (2003) The Swedish Council on Technology Assessment in Health Care (SBU) systematic overview of radiotherapy for cancer including a prospective survey of radiotherapy practice in Sweden 2001-Summary and conclusions. Acta Oncologica, 42, 357-365. doi:10.1080/02841860310010826

[16] Sawada, N.O., Dias, A.M. and Zago, M.M.F. (2006) The radiotherapy effect on the quality of life of patients with head and neck cancer. Revista Brasileira de Cancerologia, 52, 323-329.

[17] Gallasch, C.H., Alexandre, N.M.C. and Amick III, B.C.
(2007) Cross-cultural adaptation, reliability and validity of the work role functioning questionnaire to Brazilian Portuguese. Journal of Occupational Rehabilitation, 17, 701-711. doi:10.1007/s10926-007-9103-2

[18] Hébert, F. (1996) Indicators of injury: Health and safety at work: Analysis by economic activity sector 1991. Institut de Recherche Robert-Sauvé em Santé et Sécurité au Travail, Montreaul.

[19] Durand, M.J., Vachon, B., Hong, Q.N., Imbeau, D., Amick III, B.C. and Loisel, P. (2004) The cross-cultural adaptation of the work role functioning questionnaire in canadian french. International Journal of Rehabilitation Research, 27, 261-268. doi:10.1097/00004356-200412000-00002

[20] Simões, J.C. (2008) Princípios do estadiamento em oncologia. In: Simões, J.C., Gama, R.R. and Winheski, M.R., Eds., Câncer Estadiamento e Tratamento, Lemar, São Paulo.

[21] Soares, J.F. and Siqueira, A.L. (1999) Introdução à estatística médica. Departamento de Estatística UFMG, Belo Horizonte.

[22] Pryce, J., Munir, F. and Haslam, C. (2007) Cancer survivorship and work: Symptoms, supervisor response, coworker disclosure and work adjustment. Journal of Occupational Rehabilitation, 17, 83-92. doi:10.1007/s10926-006-9040-5

[23] Feuerstein, M. (2009) Cancer survivors need evidence on how optimize physical function. Journal of Cancer Survivorship, 3, 73-74. doi:10.1007/s11764-009-0090-5

[24] Bocchi, S.C.M. and Angelo, M. (2008) Between freedom and reclusion: Social support as a quality-of-life component in the family caregiver-dependent person binomial. Revista Latino-Americana de Enfermagem, 16, 15-23. doi:10.1590/S0104-11692008000100003

[25] Gotay C. (2010) Cancer survivorship: Today and tomorrow. Book review. European Journal of Cancer Care, 357, 2209-2210.

[26] Johnsson, A., Fornander, T., Rutqvist, L.E. and Olsson, M. (2010) Factors influencing return to work: A narrative study of women treated for breast cancer. European Journal of Cancer Care, 19, 317-323. doi:10.1111/j.1365-2354.2008.01043.x

[27] Munir, F., Yarker, J. and McDermott, H. (2009) Employment and the common cancers: Correlates of work ability during or following cancer treatment. Occupational Medicine, 59, 381-389. doi:10.1093/occmed/kqp088

[28] Ohguri, T., Narai, R., Funahashi, A., Nishiura, C., Yamashita, T., Yarita, K. and Korogi, Y. (2009) Limitations on work and attendance rates after employees with cancer returned to work at a single manufacturing company in Japan. Journal of Occupational Health, 51, 267-272. doi:10.1539/joh.08013

[29] Kennedy, F., Haslam, C., Munir, F. and Pryce, J. (2007) Returning to work following cancer: A qualitative exploratory study into the experience of returning to work following cancer. European Journal of Cancer Care, 16 17-25. doi:10.1111/j.1365-2354.2007.00729.x

[30] Grunfeld, E.A., Ruxon, L., Eaton, E. and Cooper, A.F. (2008) The organizational perspective on the return to 
work of employees following treatment for cancer. Journal of Occupational Rehabilitation, 18, 381-388. doi:10.1007/s10926-008-9152-1 